\title{
Improving the Learning of Engineering Mathematics via. Lab Session
}

\author{
${ }^{1}$ N. Lohgheswary, ${ }^{2}$ Z.M. Nopiah, ${ }^{3}$ E. Zakaria, ${ }^{4}$ A.A. Aziz and ${ }^{5}$ S. Salmaliza \\ ${ }^{1,2}$ Centre of Engineering and Built Environment Education, Faculty of Engineering and \\ Built Environment, Universiti Kebangsaan Malaysia, Bangi, 43600 Selangor Darul Ehsan, Malaysia \\ ${ }^{3}$ Faculty of Education, Universiti Kebangsaan Malaysia, Bangi, 43600 Selangor Darul Ehsan, Malaysia \\ ${ }^{4}$ Faculty of Computing and IT, King Abdulaziz University, 80200 Jeddah, Saudi Arabia \\ ${ }^{5}$ Centre of Engineering Education Research, Faculty of Engineering and Built Environment, \\ SEGi University, 47810 Kota Damansara, Selangor Darul Ehsan, Malaysia \\ lohgheswarynagarethinam@gmail.com
}

\begin{abstract}
Engineering Mathematics is a compulsory and core subject for any engineering disciplines. Students face problem in applying the Engineering Mathematics concepts in engineering application problems. Thus, an innovation in learning Engineering Mathematics is needed to satisfy the student's need and further to improve student's grades in the examination. A pre-test was designed based on the difficult and very difficult course outcome obtained from the previous preliminary tests. Sixty students from Electrical Engineering Department participated in the pre-test. The students were later divided into control group and experimental group. Control group students underwent 8 weeks of tutorial while the experimental group students studied the same materials in the lab using Mathematica Software. The following week, both groups of students participated in a post-test. Pre-post test results were combined and run against the Rasch analysis. Pre-post test result categorized the difficulties of the questions into four groups. They are very difficult, difficult, easy and very easy. The experimental group students did well compared to their control group counterparts. This study showed a significant improvement between the control group and the experimental group. Engineering Mathematics lab should be embedded in the Engineering Mathematics curriculum to improve the learning of Engineering Mathematics.
\end{abstract}

Key words: Engineering Mathematics innovation, learning, lab session, pre-post test, innovation, experimental group

\section{INTRODUCTION}

Engineering Mathematics is a requirement for all engineering courses as the students learn the basic computational methods that will later be applied in engineering subjects. A strong knowledge in Engineering Mathematics will ensure that a student will succeed in their later years of engineering studies. Learning Engineering Mathematics via. lectures and tutorials is the traditional method of teaching. However, there is a decline in the student's performance in a public university in Malaysia (Fuaad et al., 2014) for Engineering Mathematics subjects.

Mathematics courses have been identified as the 'high-failure rate' courses and the relevant factors that contributed to the 'high-failure' rate are examined (Eng et al., 2008). The underachievement in Mathematics courses led to the average passing rate below $70 \%$ for 4 consecutive years. These 'high-failure' rate courses had a significant element of pre-calculus and basic calculus. Findings showed that students faced problems in understanding calculus concepts. SPM Additional Mathematics was found as a good predictor for 'high failure' rate subjects. SPM is a higher secondary examination in Malaysia which is equivalent to O-level examination. In future, students with strong grade in Additional Mathematics should be recommended for science-based programs.

Poor performance of students in Mathematics has been a global issue among stakeholders in Engineering Mathematics higher education (Godwin and Chinedu, 2013). A research was conducted to investigate the causes of the poor performance of engineering students in the past four academic sessions. For instance in the

Corresponding Author: N. Lohgheswary, Faculty of Engineering and Built Environment, SEGi University, 47810 Kota Damansara, Selangor Darul Ehsan, Malaysia, lohgheswarynagarethinam@gmail.com 
session of $2011 / 2012,95 \%$ of the students secured below average and $68 \%$ failed Engineering Mathematics 4 in the Department of Mechanical Engineering. Surprisingly, the findings of the study revealed that students have positive attitude towards Engineering Mathematics. Factors that contribute to poor performance in Engineering Mathematics are poor learning environment and present coordination. Splitting the lecture schedule into two or more groups, fair assessment and fair marking of examination scripts are found to be the solution for this study.

Thus, an innovative method of learning Engineering Mathematics is proposed to give the students a concrete understanding in the subject matter. This will contribute to students achieving better grades in their examination. The objective of this srudy is to learn Engineering Mathematics via. computational tool. Recent researchers gave positive results especially in vector calculus, linear algebra and differential equations subjects (Botana et al., 2014; Chen, 2013; Zeynivannezhad, 2014).

Rasch model is a tool of analysis which has been used in the education field extensively to validate the reliability of test questions, specifically the final exam questions of Engineering Mathematics 2 (Linear Algebra) (Fuaad et al., 2014). The measurement which is the exam questions that measure student's ability was validated against Rasch model. The study concluded that student's performance was higher than the average questions. This means students are able to answer examination questions within the scope of the syllabus.

\section{MATERIALS AND METHODS}

A pre-test was conducted on sixty Electrical Engineering students from the Faculty of Engineering and Built Environment, Universiti Kebangsaan Malaysia. This test was conducted in semester 1 2016/2017. The students were in their third semester of the course. In the semester, the students were studying differential equations subject. Prior to that the students took vector calculus and linear algebra.

The course outcome related to the pre-test is a mixture of vector calculus, linear algebra and differential equations subjects. Six subjective questions were designed and the questions were grouped into easy, moderate and difficult questions. The duration of the pre-test is $2 \mathrm{~h}$. Table 1 shows the course outcomes and the level of pre-test questions. Table 2 shows the pre-post test questions.

\begin{tabular}{|c|c|c|}
\hline Weeks & Course outcome & Levels \\
\hline 1 & $\begin{array}{l}\text { Able to apply green's theorem, stoke's theorem, } \\
\text { Gaus's theorem in solving engineering problems }\end{array}$ & Moderate \\
\hline 2 & $\begin{array}{l}\text { Able to use concepts of vector space, linear } \\
\text { independent in space dimension and matrix } \\
\text { transformation }\end{array}$ & Easy \\
\hline 3 & Able to understand the concepts of power series & Moderate \\
\hline 4 & Able to apply the basic concept of partial derivatives & Moderate \\
\hline 5 & $\begin{array}{l}\text { Able to solve first and second orders of differential } \\
\text { equations }\end{array}$ & Moderate \\
\hline 6 & $\begin{array}{l}\text { Able to apply the concepts of line integral, double } \\
\text { integral and triple integral in solving engineering } \\
\text { problems }\end{array}$ & Moderate \\
\hline
\end{tabular}

\begin{tabular}{|c|c|c|}
\hline Questions & Descriptions & Marks \\
\hline 1 & $\begin{array}{l}\text { Use the Green Theorem to evaluate } \oint x y d x+x^{2} y^{3} d y \text {; } \\
\text { where, } C \text { is a triangle with vertices }(0,0),(1,0),(1,2)\end{array}$ & 6 \\
\hline 2 & $\begin{array}{l}\text { Compute the projection of }(1,2,3) \text { onto }(-2,3,-1) \\
\text { using inner product }<a, b>=2 a_{1} b_{1}+3 a_{2} b_{2}+4 a_{3} b_{3}\end{array}$ & 6 \\
\hline 3 & Obtain power series representation of in power of $(x-2) p$ & 6 \\
\hline 4 & $\begin{array}{l}\text { The plane tangent to the surface defined by } z=f(x, y) \\
\text { at the point }\left(x_{0}, y_{0}, z_{0}\right) \text { is } z=z_{0}+f_{x}\left(x_{0}, y_{0}\right)\left(x-x_{0}\right)+ \\
\text { fy }+(x, y)\left(x_{0}, y_{0}\right)\left(y-y_{0}\right) \text {. Determine the equation of the } \\
\text { plane tangent to the paraboloid } z=10-x^{2}-2 y^{2} \text { at the } \\
\text { point where } x=1 \text { and } y=2 \text {. Sketch the plane } \\
\text { tangent and the paraboloid }\end{array}$ & 9 \\
\hline 5 & $\begin{array}{l}\text { Solve the equation } d y / d x=x+y \text { with initial } \\
\text { condition } y(0)=2 \text {. Then, plot the solution }\end{array}$ & 9 \\
\hline 6 & $\begin{array}{l}\text { Find the volume of the solid that lies under the } \\
\text { paraboloid } z=x^{2}+y^{2} \text {, above the } x y \text { - and inside } \\
\text { the cylinder }(x-1)^{2}+y^{2}=1\end{array}$ & 1 \\
\hline
\end{tabular}

\section{RESULTS AND DISCUSSION}

All the pre-post test marks were entered in Excel *prn format and transferred to WINSTEPS. The WINSTEPS provides details on the summary statistics for person, summary statistics for item, fit statistics, item dimensionality and person-item distribution map.

Summary statistics for person: The summary of the statistical results for the measurement of person is given in Fig. 1. Person represents the students who sat for the pre-post test. The Cronbach alpha shows that the test reliability is 0.51 . The person reliability is 0.42 . This indicates that the students provide irregular responses to the items. We assume that they can answer the questions but in the actual case they cannot answer the questions. Some of the pre-post test questions were less likely to be answerable and some other questions could be answered successfully.

From Fig. 1, the person separation is 0.86 logit. Therefore, the students cannot be divided into any group. Logit is a unit obtained from transforming ordinal data into an interval scale (Zeynivannezhad, 2014). The person mean is -0.28 . This means that student's ability to answer the pre-post tests is lesser than the expected performance. 
J. Eng. Applied Sci., 14 (19): 6964-6970, 2019

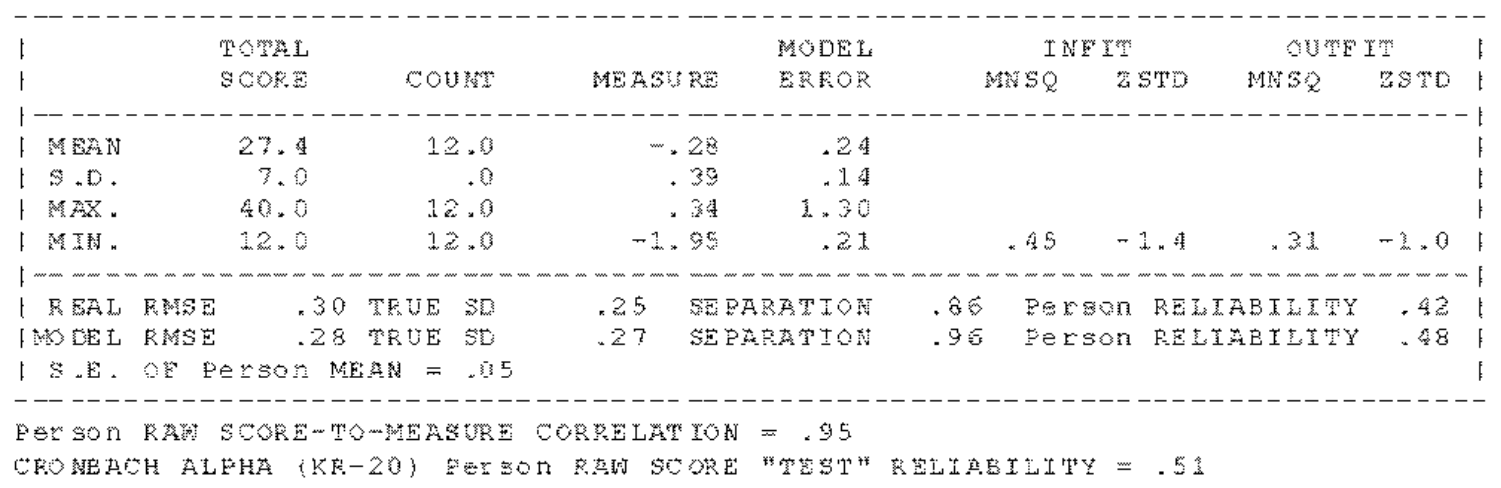

Fig. 1: Summary statistics for person

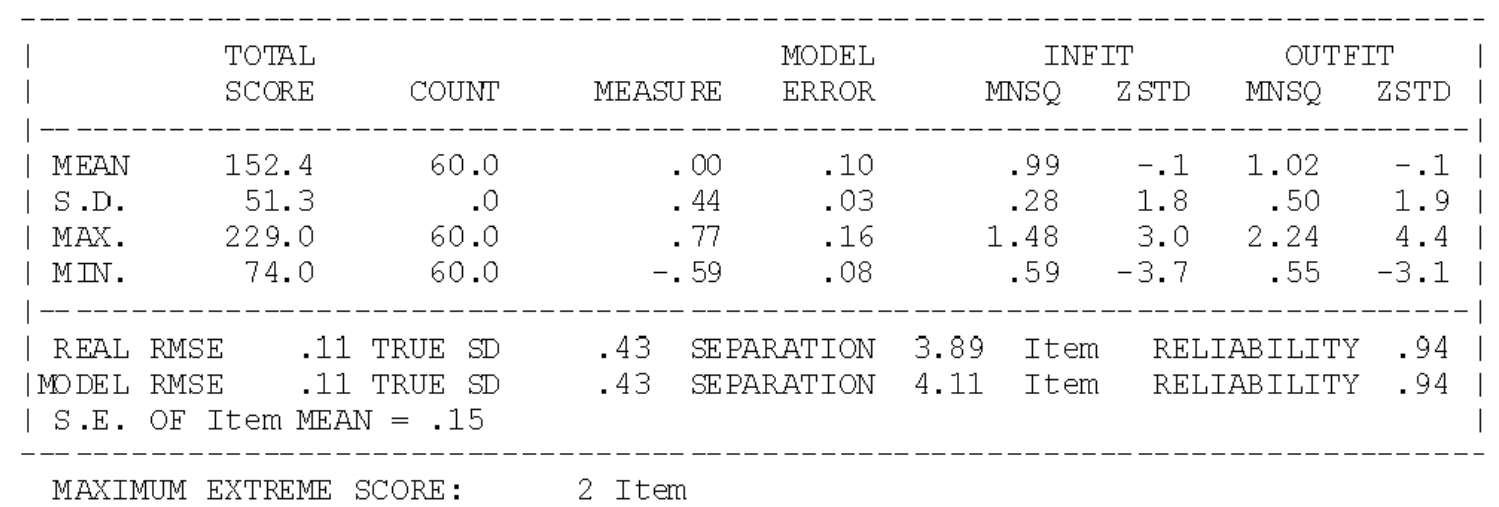

Fig. 2: Summary statistics for item

The negative mean also reflects that the students are less competent. The maximum of person on the difficulty logit is +0.34 and the minimum is -1.95 .

Summary statistics for item: Figure 2 represents the measurement of items involved in this study. Items represent the questions tested on the pre-post test. The item reliability is 0.94 . This indicates good item difficulty spread.

Item separation means the gap between the items of different levels of difficulty. A higher value of separation indicates that there is a shortage of items. The item separation is 3.89. This means that the questions can be classified into four groups. The item mean is 0 . The maximum item on the logit ruler is 0.77 while the minimum item is -0.59 . Figure 2 also indicates that there is 2 maximum items. This means there are two questions that are extremely difficult for the students to answer.

Summary statistics for item: Figure 3 shows the fit statistics for the pre-post test. Rasch model examined the item fit by infit and outfit (Draugalis and Jackson,
2004). A point-measure correlation calculates the index of the item discrimination where the item with greater value might be too good compared to other items (Othman et al., 2012). The point measure correlation value must be within $0.4<\mathrm{x}<0.8$. Item $\mathrm{A} 1, \mathrm{~A} 4, \mathrm{~A} 6, \mathrm{~A} 5, \mathrm{~A} 2$ and $\mathrm{A} 3$ within this range. Item B3, B6, B5, B4, B2 and B1 are out of the range. Next, the range for outfit mean square is $0.5<\mathrm{MNSQ}<1.5$. From item B1-B6, only item B3 and B6 are out of the mean square range. Lastly the range for outfit $\mathrm{z}$-standard is $-2<\mathrm{z}<2$. All the items except item B3 and B6 are within the range. Since, item B3 and B6 are out of range for all the three measurements, therefore, question B3 and B6 are considered misfit for the pre-post test. These two questions are extremely difficult for all the students to answer.

Item dimensionality: Figure 4 shows the item dimensionality for pre-post test. The unexplained variance (total) from Fig. 4 is $39.3 \%$. Raw variance explained by measure $>20 \%$ is accepted as an indicat or of uni-dimensionality (Reckase, 1979). Even though the raw variance explained by measure is $39.3<40 \%$ but 
J. Eng. Applied Sci., 14 (19): 6964-6970, 2019

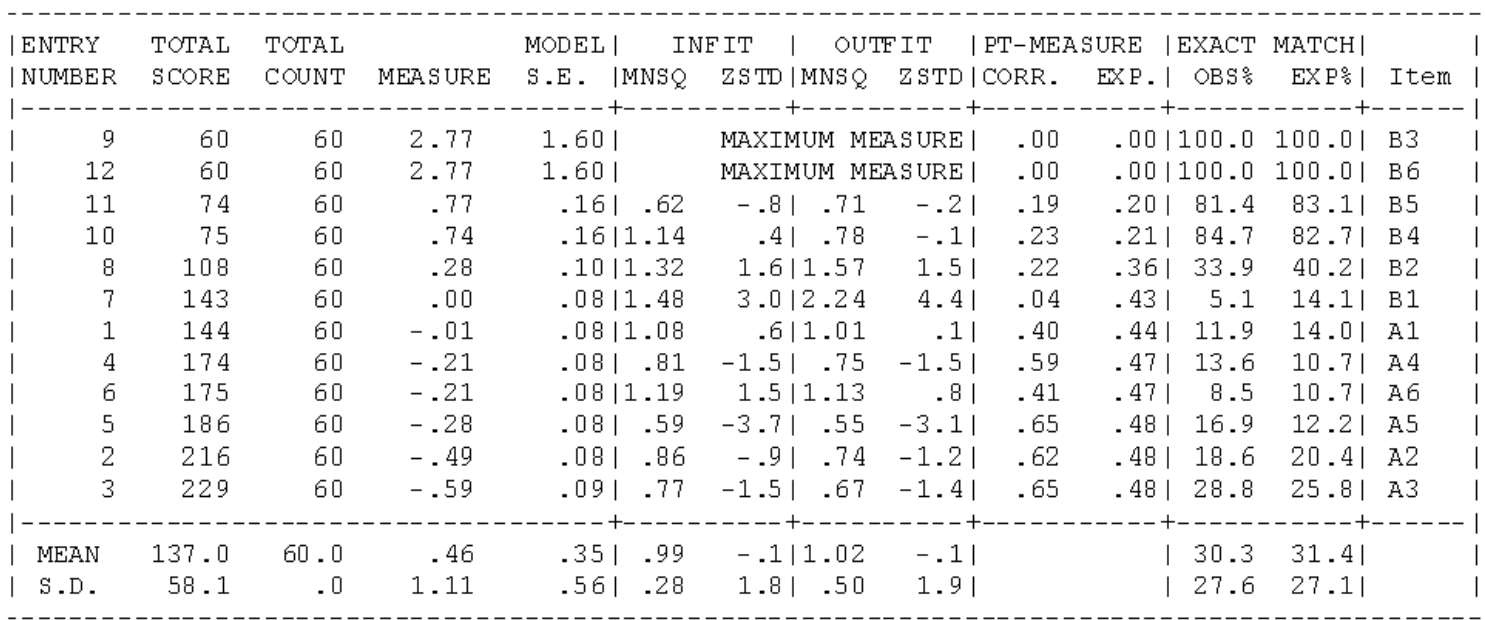

Fig. 3: Fit statistics

\begin{tabular}{|c|c|c|c|c|c|}
\hline & & $--\frac{T_{2}}{n}$ & mirical & -- & Model $1 \Leftrightarrow d$ \\
\hline 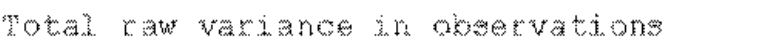 & $=$ & 签. & 190.00 & & 100. \\
\hline Ray vartande explained ky measures & $=$ & 6.5 & 39.38 & & $30.0 \%$ \\
\hline Ray vawane explatned by pargons & $=$ & 1.0 & 6.18 & & 管. 1. \\
\hline Kaw Vartance exphaned by jtem & $=$ & 5.5 & $33.2 \mathrm{~g}$ & & $3 \hat{3} .9 \%$ \\
\hline 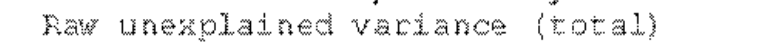 & $=$ & \pm 0.0 & 60.78 & $100 * 0$, & 61.0 \\
\hline Unezplned variance in 1 st contrast & $=$ & 2.4 & 14.68 & 24.03 & \\
\hline 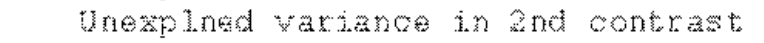 & بي & 1.7 & 1.0 .45 & 1.7. 7.13 & \\
\hline Unexplned variance in 3 rd contrast & $=$ & 1.5 & $5.0 \%$ & 14.93 & \\
\hline Unexplngad warianoe in ath contrast & $=$ & $1, \hat{2}$ & 7.3 .3 & 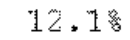 & \\
\hline Unexplned variance in sth contrast & $=$ & .9 & 5.34 & $8.7 \%$ & \\
\hline
\end{tabular}

Fig. 4: Item dimensionality

the 'noise' or disturbance is still acceptable. The disturbance is indicating that some students have difficulties in answering the questions but the pattern is still acceptable.

The unexplained variance in 1st contrast explains $14.6 \%$ of the variance. This value is within the acceptable range of $5-15 \%$. Thus, the test questions are uni-dimensional.

Person-item distribution map: Figure 5 represents the item distribution map where Rasch provides the location of all the students on the vertical logit ruler indicated by dashed vertical line. As indicated, the higher the person was located on the map, the most competent the student. In contrast, the question is like the hurdle to the students. The lower a question on the ruler, the easier the question will be and vice versa.

The summary statistics of person indicated that the students cannot be classified into any group. Therefore, the ability of each and every student is the same. From
Fig. 5, the left side of the dashed line shows the control group and experimental group of students. For example, C21, means the student numbered 21 from the control group. E17 means the student numbered 17 from the experimental group. Figure 5 combines both the results of the pre-test and post-test.

B3 means question 3 for pre-test. A3 means question 3 for post-test. From the summary statistics for items, the questions can be grouped into very difficult, difficult, moderate and easy. Based on Table 1 , question $1,3,4,5$ and 6 should be at moderate level. Question 2 should be positioned at moderate level. Based on Fig. 3, questions B1 and B2 are categorized as difficult questions. Question B3, B4, B5 and B6 are in the very difficult category. It can be noted that B3 and B6 are the two extreme questions which resulted in the summary statistics for item. This clearly states that the pre-test questions can be grouped into difficult and very difficult categories, although, it is supposed to be in easy and moderate groups. 
J. Eng. Applied Sci., 14 (19): 6964-6970, 2019
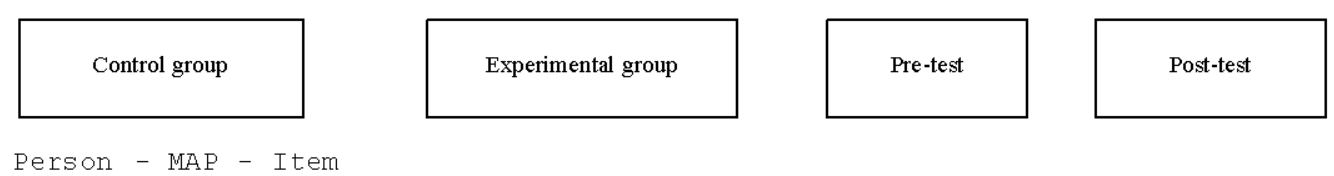

Person - MAP - Item

1

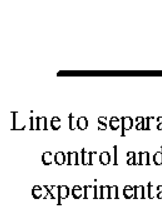

xperiment

group
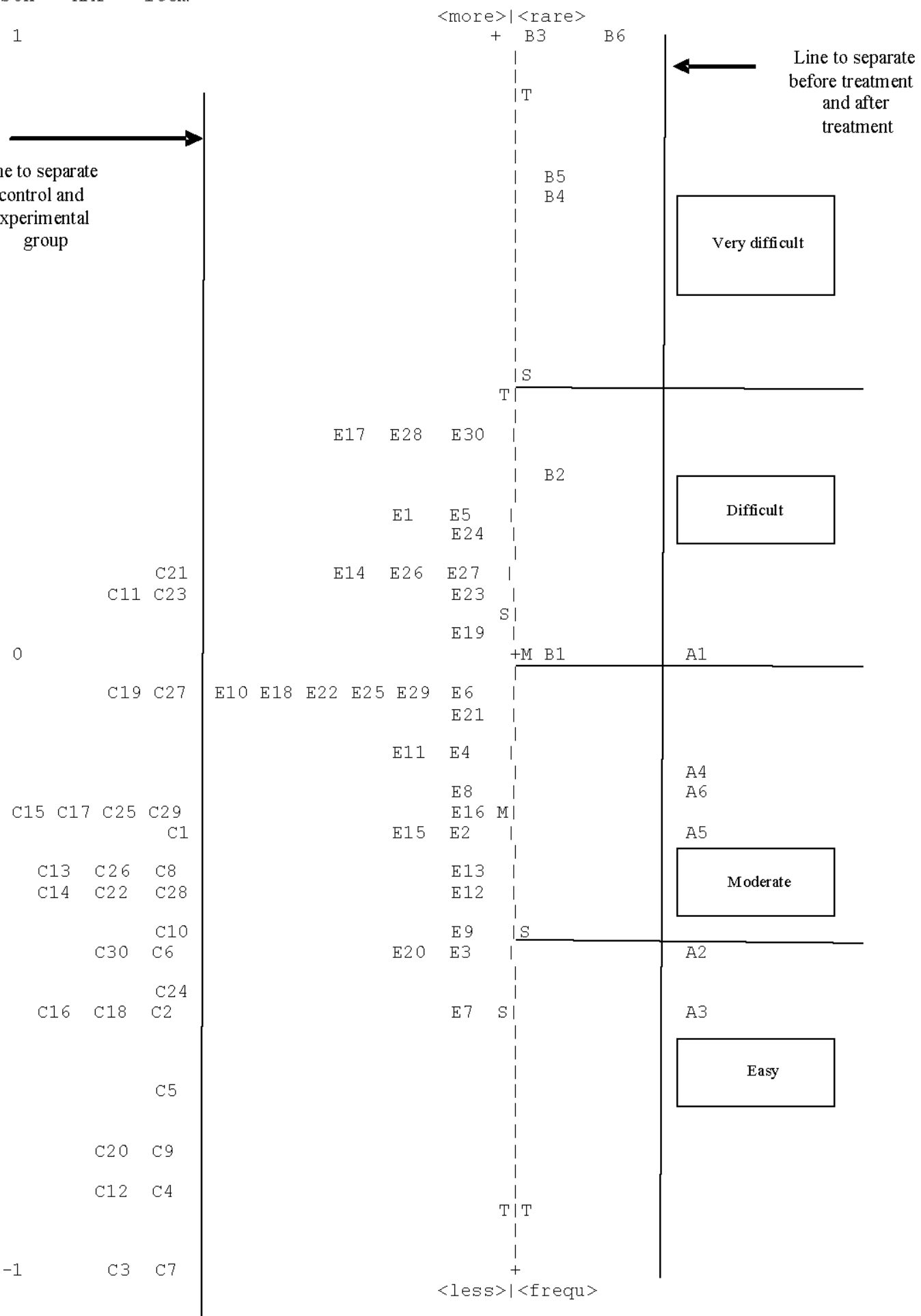

Fig. 5: Person-item distribution map 
After 8 weeks of tutorials and lab sessions, the post-test questions can be classified into three different groups. They are very easy, easy and difficult groups. Question A2 and A3 were categorized into very easy group. Questions A4, A5 and A6 were categorized into easy group. Question Al was categorized into difficult group. Generally, the post-test result had improved with the aid of the tutorials and lab sessions.

The person-item distribution map gives an insight on the performance of the control and experimental groups. The experimental students perform better than the control students. The experimental student's ranking was better than the control students. This can be seen on the left side of the dashed line. There are 22 students who are above the mean line for the experimental group. For the control group, there are 9 students who are only above the mean line. This proves that learning via. Mathematica boosts student's performance in Engineering Mathematics.

This study found out that student saves a lot of time doing the computation via. Mathematica lab. This means the number of steps for each questions in computation using Mathematica is less compared to the manual calculation. So, students obtained the answer quickly using Mathematica. Students too find that drawing graphs using Mathematica is much easier than drawing manually. Thus, student's visualizing power increased using Mathematica Software. Therefore, students from the experimental group perform much better than the control group. It is noted that during the laboratorial and tutorial sessions, students are given the same question to both of the group. This is to avoid bias to any group.

The control group of students are located lower than the experimental group of students in the person-item distribution map. There are 7 students from the control group who are located at the bottom of easy group of questions. They are C5, C20, C9, C12, C4, C3 and C7. For this group of students, all the pre-post test questions are very difficult to answer. Checking on their previous semester results, it is found that these students obtained grades $\mathrm{D}$ to grade $\mathrm{C}+$ for their vector calculus final examination in their first semester. This means that these students have problems in Engineering Mathematics subjects as soon as they entered university. These students obtained grade $\mathrm{C}$ to grade $\mathrm{B}+$ in linear algebra final examination in their second semester. This reflects that students who are poor in vector calculus and and average in linear algebra still perform badly in Engineering Mathematics topics.

There are only 3 students from the control group who manage to answer question $\mathrm{A} 1$ which falls into the difficult category. They are C21, C11 and C23. These three students perform well in the linear algebra final examination. Their results were $\mathrm{B}, \mathrm{B}+$ and $\mathrm{A}-$. Comparatively, students from experimental group E17, E28, E30, E1, E5, E24, E14, E26, E27, E23 and E19 could manage question A1. Almost all of them scored $\mathrm{A}$ and $\mathrm{A}$ - in their linear algebra final examination in the previous semester. This clearly states that the performance of the experimental group of students is relatively better than the control group of students.

\section{CONCLUSION}

Poor performance in Engineering Mathematics has been an issue for academicians both internally and internationally. Many factors contributed to this issue. As a remedy, tutorial classes parallel with laboratory sessions were introduced in this study. About 60 students were chosen for this study from a public university in Malaysia. The students took a pre-test to verify the ability of the students in vector calculus, linear algebra and differential equation. After the pre-test, the students underwent two different treatments. The 30 students were grouped in control group and given tutorial classes. About 30 other students were grouped in experimental group and underwent laboratorial sessions using Mathematica Software.

Lab sessions help to reduce tedious calculation and to visualize graphs in Engineering Mathematics. Thus, it will help students in the exam. The laboratory sessions for Engineering Mathematics will enable the students to visualize the abstract concepts and to understand the subjects better. Thus, it will enable a student to achieve higher grades in the final examination or test.

\section{ACKNOWLEDGEMENT}

The researchers wish to express gratitude towards SEGi University and Universiti Kebangsaan Malaysia for supporting the research.

\section{REFERENCES}

Botana, F., M.A. Abanades and J. Escribano, 2014. Using a free open source software to teach mathematics. Comput. Appl. Eng. Educ., 22: 728-735.

Chen, F.X., 2013. Research of scientific computing in the engineering linear algebra teaching. Appl. Mech. Mater., 333: 2218-2221.

Draugalis, J.R. and T.R. Jackson, 2004. Objective curricular evaluation: Applying the Rasch model to a cumulative examination. Am. J. Pharm. Educ., 68: $1-12$. 
Eng, T.H., V.L. Li and N.H.B. Julaihi, 2008. The impact of high-failure rate'mathematics courses on UiTM sarawak full-time diploma students academic performance. Master Thesis, Universiti Teknologi MARA, Malaysia.

Fuaad, N.F.A., Z.M. Nopiah, N.M. Tawil, H. Othman and I. Asshaari et al., 2014. Blooms separation of the final exam of Engineering Mathematics II: Item reliability using rasch measurement model. AIP. Conf. Proc., 1602: 508-513.

Godwin, H.C. and J.O. Chinedu, 2013. Critical analysis of the recent poor performance of engineering students in Engineering Mathematics: A case Nmadi Azikiwe University, Awka, Nigeria. Intl. J. Eng. Res. Technol., 2: $2587-2601$.
Othman, H., I. Asshaari, H. Bahaludin, Z.M. Nopiah and N.A. Ismail, 2012. Application of Rasch measurement model in reliability and quality evaluation of examination paper for Engineering Mathematics courses. Procedia Social Behav. Sci., 60: 163-171.

Reckase, M.D., 1979. Unifactor latent trait models applied to multifactor tests: Results and implications. J. Educ. Stat., 4: 207-230.

Zeynivannezhad, F., 2014. Mathematical thinking in differential equations through a computer algebra system. $\mathrm{PhD}$ Thesis, University of Technology, Malaysia, Johor Bahru, Malaysia. 